$10-2000$

\title{
Are Invisible Hands Good Hands? Moral Hazard, Competition, and the Second-Best in Health Care Markets
}

\author{
Martin Gaynor \\ Carnegie Mellon University
}

Deborah Haas-Wilson

Smith College,dhwilson@smith.edu

William B. Vogt

Carnegie Mellon University

Follow this and additional works at: https://scholarworks.smith.edu/eco_facpubs

Part of the Economics Commons

\section{Recommended Citation}

Gaynor, Martin; Haas-Wilson, Deborah; and Vogt, William B., "Are Invisible Hands Good Hands? Moral Hazard, Competition, and the Second-Best in Health Care Markets" (2000). Economics: Faculty Publications, Smith College, Northampton, MA.

https://scholarworks.smith.edu/eco_facpubs/10 
Are Invisible Hands Good Hands? Moral Hazard, Competition, and the Second-Best in Health Care Markets

Author(s): Martin Gaynor, Deborah Haas-Wilson and William B. Vogt

Source: Journal of Political Economy, Vol. 108, No. 5 (October 2000), pp. 992-1005

Published by: The University of Chicago Press

Stable URL: https://www.jstor.org/stable/10.1086/317672

JSTOR is a not-for-profit service that helps scholars, researchers, and students discover, use, and build upon a wide range of content in a trusted digital archive. We use information technology and tools to increase productivity and facilitate new forms of scholarship. For more information about JSTOR, please contact support@jstor.org.

Your use of the JSTOR archive indicates your acceptance of the Terms \& Conditions of Use, available at https://about.jstor.org/terms 


\title{
Are Invisible Hands Good Hands? Moral Hazard, Competition, and the Second-Best in Health Care Markets
}

\author{
Martin Gaynor \\ Carnegie Mellon University and National Bureau of Economic Research \\ Deborah Haas-Wilson
}

Smith College

William B. Vogt

Carnegie Mellon University and National Bureau of Economic Research

\begin{abstract}
The nature and normative properties of competition in health care markets have long been the subject of much debate. In this paper we consider what the optimal benchmark is in the presence of moral hazard effects on consumption due to health insurance. Intuitively, it seems that imperfect competition in the health care market may constrain this moral hazard by increasing prices. We show that this intuition cannot be correct if insurance markets are competitive. A competitive insurance market will always produce a contract that leaves consumers at least as well off under lower prices as under higher prices.
\end{abstract}

We have benefited from helpful comments by Ashish Arora, David Dranove, Ted Frech, Cobi Glazer, Dan Kessler, Tom McGuire, Mark Pauly, Jim Rebitzer, Bill Rogerson, Dennis Yao, the editor, and an anonymous referee as well as participants in seminars at Case Western Reserve, Cornell, Penn, the third biennial conference on the Industrial Organization of Health Care, and the 1998 American Economic Association meetings. This research was supported in part by a grant from the Robert Wood Johnson Foundation. The usual caveat applies.

[Journal of Political Economy, 2000, vol. 108, no. 5]

(C) 2000 by The University of Chicago. All rights reserved. 0022-3808/2000/10805-0005\$02.50 


\section{Introduction}

The nature and normative properties of competition in health care markets have long been the subject of debate. Many policy makers have reservations toward competition in health care markets. For example, hospital entry, investment, and service offerings have been regulated via state certificate of need regulations and health planning agencies, and pricing has been regulated by hospital "all-payer" regulation in some states and by Medicare and Medicaid. Additionally, federal antitrust enforcement agencies were not vigorous in health care prior to the late 1970 s. Currently, as consolidation rapidly occurs in health care markets, concern about reduced competition has arisen (Gaynor and HaasWilson 1999).

Antitrust enforcement policy in health has been based on the view that health care is like all other industries (e.g., Weller 1983; Bingaman 1995). Thus competition serves as the benchmark. In particular, distortions in health care markets, and their impacts on the socially optimal amount of competition, are not considered. Some have argued that particular distortions that characterize health care markets imply that competition is not optimal (Crew 1969; Robinson and Luft 1985; Lynk 1995).

In this paper we consider what the optimal benchmark is in the presence of moral hazard. Moral hazard is widely recognized as one of the most important distortions in health care markets. In general, economic analysis suggests that marginal cost pricing leads to static Pareto-optimal allocations. In health care markets, however, moral hazard due to health insurance leads to excess consumption, in the sense that insured individuals will consume medical services past the point at which the marginal utility of an additional service is equal to its marginal cost (Arrow 1963; Pauly 1968). In this context, it is not obvious that price equal to marginal cost is optimal in the medical market.

While the problem of optimal insurance in the presence of moral hazard has been extensively analyzed (e.g., Arrow 1963; Pauly 1968; Zeckhauser 1970), the issue of the optimal amount of competition in the presence of moral hazard has not. Intuitively, it seems that imperfect competition in the medical care market may constrain this moral hazard by increasing prices. This intuition derives from the theory of the second-best, in which a second distortion may improve performance in a market already immutably distorted. An early paper by Crew (1969) reaches this conclusion using graphical arguments. This intuition has been established as a kind of folk theorem in health economics (Frech 1996; Pauly 1998; Folland, Goodman, and Stano 2001) and has influenced thinking about the optimality of competition in medical markets (e.g., Dor and Rizzo 1995). 
An important limitation of this result is that the endogenous determination of the degree of consumer cost sharing by the insurance industry is not considered. These papers do not allow insurers to alter coinsurance rates in response to changes in medical prices. Insurers do appear to alter their policies in response to medical prices (Phelps 1973; Frech 1979).

We model the optimal amount of health insurance and competition, given risk aversion and moral hazard. We show that if insurance markets are competitive and insurers set the degree of consumer cost sharing optimally, then contrary to the standard intuition, adding another distortion does not improve welfare. Since the insurer has already made the trade-off between risk reduction and moral hazard, a price increase in the medical market cannot wring any further surplus out of the resulting decrease in moral hazard. Thus imperfect competition in medical markets cannot have efficiency-enhancing effects, even in the presence of moral hazard. Furthermore, when the medical market is not competitive and already exhibits prices above marginal costs, price increases lead to lower welfare and price decreases lead to higher welfare.

The principal claim of this paper is that most of economists' intuition regarding the welfare effects of price changes in markets not distorted by moral hazard applies quite well to markets in which decision making by consumers is distorted by moral hazard. In particular, lower prices are better for consumers than higher prices. Furthermore, the gain to consumers from lowering price from supramarginal cost levels to marginal costs outweighs the loss of profit to the medical industry.

The basic model and setup of the paper are presented in Section II. Section III contains the main analysis in the paper: the normative properties of competition when the insurance market is competitive and free to respond optimally to price levels in the medical market. Section IV summarizes the discussion and presents conclusions.

\section{The Model}

We use a standard model of insurance. There is a (measure 1) continuum of consumers, all of whom are identical except with regard to the realization of a random variable, $\epsilon$, which is a shock to health. Consumers are uncertain ex ante with regard to the realization of $\epsilon$, although they know its distribution. The size of the loss associated with a realization of $\epsilon$ is privately known to the consumer ex post (or at least is not verifiable to a court or other contract enforcer) and is remediable (at least in part) through the consumption of a good, which we shall call the medical good. The medical good has a price, $p$, and is produced at a constant marginal cost, $c$. Insurance contracts take the form of a premium, assessed with certainty, and a partial cost reimbursement for 
consumption of the medical good. A contract is a pair $(\tau, m)$, where $m$ is the premium paid by the consumer to the insurance company, and $\tau \in[0, p]$ is the price faced by the consumer for the medical good. The insurance company implements this price by facing the consumer with a coinsurance rate $\theta=\tau / p$ so that the insurance company reimburses the consumer a fraction $1-\theta$ of his expenditures on the medical good.

Consumption of medical care is determined in the following way. Consider a consumer possessing an insurance contract, $(\tau, m)$. After the consumer's loss, $\epsilon$, is realized, he solves

$$
\max _{x} U(Y-\tau x-m, x, \epsilon)
$$

subject to

$$
\begin{aligned}
& x \geq 0, \\
& I \equiv Y-\tau x-m \geq 0,
\end{aligned}
$$

where $Y$ is the consumer's income, $x$ is the quantity of the medical good consumed, and $I$ is consumption of a composite nonmedical commodity. We denote the solution to this problem $x^{*}(Y-m, \tau, \epsilon)$. Substituting $x^{*}$ into $U$ yields the consumer's indirect utility function, $V(Y-m, \tau, \epsilon)$. Taking expectations over $\epsilon$ defines the expected indirect utility function:

$$
E V(Y-m, \tau)=E\{V(Y-m, \tau, \epsilon)\} .
$$

We assume throughout that $U_{1}>0$,

$$
\frac{U_{1}}{U_{2}} \underset{I \rightarrow 0}{\rightarrow} \infty, \frac{U_{1}}{U_{2}} \underset{x \rightarrow 0}{\rightarrow} 0,
$$

and the insurance industry encounters no administrative costs.

The profits of the medical and insurance industries may be calculated as follows:

$$
\begin{aligned}
\pi_{i} & =m-E\left\{(p-\tau) x^{*}\right\}, \\
\pi_{m} & =E\left\{(p-c) x^{*}\right\} .
\end{aligned}
$$

The consumer will consume the medical good to the point at which $U_{2} / U_{1}=\tau$. If the medical good is normal, if there is a perfectly competitive medical market (so that $p=c$ ), and if $\tau<p$, then this consumption will not be optimal, ex post. Too much of the medical good will be consumed.

A graphical depiction (based on Crew [1969]) of this standard analysis is presented in figure 1 . The ex post demand curve for the medical good is denoted $D(p)$. Insurance contracts distort demand by facing consumers with only a proportion $\theta$ of their expenses for medical care, 


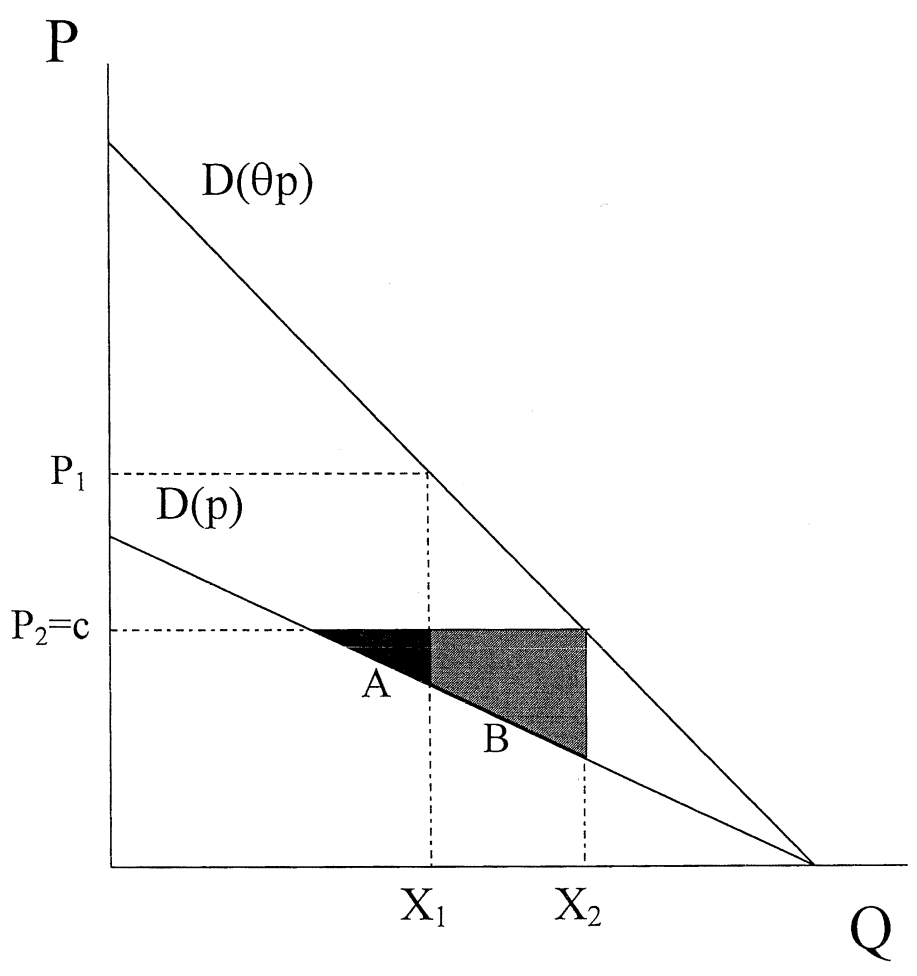

Fig. 1.-Standard analysis

and this leads to the distorted ex post demand curve $D(\theta p)$. The ex post efficiency loss due to moral hazard at price $P_{1}$ is the area $A$. When price falls from $P_{1}$ to marginal cost at $P_{2}$, welfare loss increases to the area $A+B$. So when prices decrease from supramarginal cost levels to marginal costs, there is an additional welfare loss, the area $B$.

However, ex post efficiency is not a sensible welfare criterion here since it ignores the benefits to obtaining insurance ex ante (Feldstein 1973; Feldman and Dowd 1991). Our purpose in the next section is to evaluate under what conditions a price increase (relative to marginal cost pricing) in the medical market can improve ex ante efficiency.

\section{The Second-Best}

While the argument summarized in figure 1 is intuitive, it turns out that it is right only if the insurance market does not respond to the price change in the medical market (i.e., it assumes that $\theta$ stays the same after 
the change in price). In this section, we relax that assumption and see that, in contrast to figure 1, price increases above marginal costs lead to declines in welfare.

For the propositions below, the medical market's price is set (by fiat or by an oligopoly or competitive equilibrium), and the medical producers supply whatever quantity is demanded at some constant marginal cost, $c$. The insurance industry is competitive; thus we assume that it chooses insurance policies $(\tau, m)$ that maximize consumer welfare, conditional on a break-even constraint. We assume that consumers obtain insurance from one insurer at the terms specified in the insurance contract, that is, that insurers may write enforceable contracts forbidding consumers from purchasing multiple policies. Arnott and Stiglitz (1991) have termed this an "exclusive (quantity) contract." A competitive equilibrium exists in this case and is constrained efficient when there is only one consumer good (Pauly 1974; Arnott and Stiglitz 1991).

\section{A. Consumer Welfare}

In proposition 1, we show that consumers benefit from a price decline in the medical market. In the discussion afterward, we show that the result of proposition 1 holds even for a monopolist insurer. Proposition 2 then shows that social welfare rises when price falls, as long as price is above marginal cost. Again, the discussion afterward shows that this result applies to a monopolist insurer as well.

Proposition 1. Assume that the insurance market is competitive and $U$ is nondecreasing in its first argument. Then consumers are (weakly) better off if price decreases in the medical market.

Proof. The problem of the competitive insurance industry is to

$$
\max _{\tau, m} E V(Y-m, \tau)
$$

subject to

$$
\begin{aligned}
& m \geq E\left\{(p-\tau) x^{*}(\tau, \epsilon)\right\}, \\
& 0 \leq \tau \leq p .
\end{aligned}
$$

We shall consider a price decline from some price $p^{1}$ to $p^{2}$. We shall show that, for each feasible contract under $p^{1}$, there exists a feasible contract under $p^{2}$ that leaves consumers at least as well off. Let $\left(\tau^{1}, m^{1}\right)$ be a feasible contract under price $p^{1}$. There are two possibilities to be considered: $\tau^{1} \leq p^{2}$ and $\tau^{1}>p^{2}$.

First, suppose that $\tau^{1} \leq p^{2}$. Now consider a contract under price $p^{2}<p^{1}$. Choose $m^{1}=m^{2}$ and $\tau^{1}=\tau^{2}$. Observe that the consumer makes precisely the same choice of $x$, pays the same amount for it out of pocket, 
and pays the same premium as under the optimal contract at price $p^{1}$. Thus he is as well off under this contract as he was under the contract at price $p^{1}$. Since $p^{2} \leq p^{1}$, this new contract is feasible (it does not violate the insurance industry's break-even constraint) at the new price.

Now suppose that $\tau^{1}>p^{2}$. Consider moving the consumer to a situation of no insurance, $\tau^{2}=p^{2}$ and $m^{2}=0$. Clearly this is a feasible choice for the insurer. Now, we check that the consumer is better off at this contract and the lower price than he was at the old contract and price. Consider the consumer's optimization problem again: $\max _{x} U(Y-\tau x-m, x, \epsilon)$. Under the new price and contract, the consumer faces a lower effective price $\left(\tau^{1}>p^{2}\right)$ and a higher effective income $\left(m^{1} \geq 0\right)$ for each realization of $\epsilon$. Standard results from consumer theory imply that this will not decrease utility if $U$ is nondecreasing in its first argument, as we have assumed. Q.E.D.

This proposition establishes that consumer welfare is decreasing in the price of the medical good. This implies that competition is indeed second-best optimal, from the consumer's point of view, in medical markets in the presence of moral hazard.

Another result worth mentioning is that consumers' welfare is decreasing in medical price even if the insurance industry is monopolized (but not monopsonized). The insurance industry then solves

$$
\max _{\tau, m}\left\{m-(p-\tau) E\left\{x^{*}(\tau, \epsilon)\right\}\right\}
$$

subject to

$$
\begin{aligned}
& 0 \leq \tau \leq p, \\
& E V(Y-m, \tau) \geq E V(Y, p) .
\end{aligned}
$$

As long as utility is increasing in its first argument, the "participation constraint" will bind at the solution to this problem. Since a decrease in price clearly increases $E V(Y, p)$, a decrease in price will improve consumers' welfare. ${ }^{1}$

\section{B. Social Welfare}

A price decrease in the medical market may benefit consumers; however, it is also likely to harm producers in the medical industry (i.e., profits are likely to fall). To consider the impacts on social welfare, we obviously

\footnotetext{
${ }^{1}$ We note that this result follows trivially from the nature of insurance demand in this model. Since consumers buy either a fixed quantity of insurance or none at all, monopoly has no effects on quantity and thus no efficiency effects. The monopolist simply raises its price to extract the entire risk premium from consumers.
} 
want to see whether the harm to producers is smaller than the benefit to consumers of a price decline.

To avoid analytical difficulties, we substantially restrict the form of the utility function to eliminate income effects:

$$
\begin{gathered}
U(Y-\tau x-m, x, \epsilon)=\nu(Y-\tau x-m+g(x, \epsilon)), \\
\nu(x)=-\exp (-r x), \\
g_{1}>0, g_{2}<0, g_{12}>0, g_{11}<0 .
\end{gathered}
$$

The separability inside $\nu$ guarantees that there are no income effects ex post. The assumption of an exponential form for $\nu$ guarantees that there are no income effects ex ante. The two assumptions together are the familiar "no income effects" formulation used frequently in partial equilibrium welfare analysis (Willig 1976). As also is typical, we assume that income is great enough that consumers will never wish to spend all of their income on the medical good. The assumptions on $g$ capture the fact that $\epsilon$ represents "medical need." Higher $\epsilon$ causes both lower utility and an increase in the efficacy of the medical good in producing utility.

The competitive insurance industry's problem is as above:

$$
\max _{\tau, m} E V(Y-m, \tau)
$$

subject to

$$
\begin{aligned}
& m \geq E\left\{(p-\tau) x^{*}(\tau, \epsilon)\right\}, \\
& 0 \leq \tau \leq p .
\end{aligned}
$$

This problem has a solution since the theorem of the maximum ensures that the insurance industry is optimizing a continuous function

$$
\left\{E\left\{\nu\left(-m(\tau, p)+\max _{x}\{-\tau x+g(x, \epsilon)\}\right)\right\}\right\}
$$

over a compact set $[0, p]$. Furthermore, we show below in lemma 1 that the optimal effective price is $\tau<p$.

The insurance industry's problem, in general, is not concave; nor is it quasi-concave. Furthermore, without additional assumptions, we cannot rule out $\tau=0$ as a solution. Since different choices of (consumer optimal) $\tau$ lead to different levels of social welfare through their effects on $\pi_{m}$, levels of welfare will be determined by which $\tau$ is chosen for each price. In what follows, we shall assume that $\tau(p)$ is a selection from the optimal correspondence.

Since there are no income effects, we may calculate welfare (in dollars) simply by summing medical industry profits and consumer willingness to pay. Alternatively, we may calculate welfare (in utils) by adding 
medical industry profits to the consumer's income. For a particular price in the medical market, $p$, and profits in the medical market, $\pi_{m}$, welfare is

$$
\begin{aligned}
W\left(p, Y, \pi_{m}\right)= & \exp \left[-r\left(Y+\pi_{m}\right)\right] \max _{\tau \in[0, p]}\{E\{\nu(-m(\tau, p) \\
& \left.\left.\left.+\max _{x}\{-\tau x+g(x, \epsilon)\}\right)\right\}\right\} .
\end{aligned}
$$

Of course, $\pi_{m}$ is determined in equilibrium as $\pi_{m}=(p-c) x^{*}(\tau)$. By our assumption of no income effects, the maximizing $\tau$ is not affected by the level of $\pi_{m}$. We write the (selection from the set of) optimal insurance contract $\left(\tau^{*}(p), m^{*}(p)\right)$. Then welfare at a price $p$ is defined to be

$$
W(p)=W\left(p, Y,(p-c) x^{*}\left(\tau^{*}\right)\right) .
$$

We now establish a series of lemmas, which we then use to prove our main proposition. We first adapt the following result of Zeckhauser (1970) to our setting.

Lemma 1 . In any optimal insurance contract, $\tau \in[0, p)$.

Proof. See the Appendix.

For the next lemma, fix a price $p_{0}>0$ and (inductively) construct sequences $\left\{p_{n}\right\}$ and $\left\{\tau_{n}\right\}$ as follows. Choose

$$
\tau_{n} \in \underset{\tau \in\left[0, p_{n}\right]}{\arg \max }\left\{E\left\{\nu\left(-m\left(\tau, p_{n}\right)+\max _{x}\{-\tau x+g(x, \epsilon)\}\right)\right\}\right\} .
$$

Set $p_{n+1}=\tau_{n}$.

Lemma 2. $p_{n} \rightarrow 0$.

Proof. See the Appendix.

Lemma 3. Any $\tau(p)$, a selection from

$$
\begin{gathered}
\underset{\tau \in[0, p]}{\arg \max } E\{U(Y-m(\tau, p)-\tau x(\tau, \epsilon), x(\tau, \epsilon), \epsilon)\}, \\
m(\tau, p)=(p-\tau) E\{x(\tau, \epsilon)\},
\end{gathered}
$$

with a utility function having no income effects, is nondecreasing in $p$.

Proof. See the Appendix.

Lemma 4. Fix $p^{1}>c$. Let $\left(\tau^{1}, m^{1}\right)$ be an associated optimal contract and $\pi_{m}^{1}$ the medical industry profit. Let $p^{2}$ be a price satisfying $p^{2}>c$ and $\tau^{1} \leq p^{2} \leq p^{1}$ with associated optimal contract $\left(\tau^{2}, m^{2}\right)$ and medical industry profit $\pi_{m}^{2}$. Then $W\left(p^{1}\right) \leq W\left(p^{2}\right)$.

Proof. See the Appendix.

We now establish the main result of this section: that welfare is declining in price, for prices greater than marginal cost.

Proposition 2. If $0 \leq c \leq p \leq p^{\prime}$, then $W(p) \geq W\left(p^{\prime}\right)$.

Proof. Construct sequences, $\left\{p_{i}\right\}$ and $\left\{\tau_{n}\right\}$, as in the discussion before 
lemma 2, using $p^{\prime}$ as the starting point. Since $p_{n} \rightarrow 0, p_{n}<p$ eventually. Find the least $n$, call it $N$, for which $p_{n}<p$. We claim that

$$
W\left(p^{\prime}\right)=W\left(p_{0}\right) \leq W\left(p_{1}\right) \leq W\left(p_{2}\right) \leq \cdots \leq W\left(p_{N-1}\right) \leq W(p) .
$$

The first equality follows from the definition of $\left\{p_{n}\right\}$. Consider any arbitrary inequality in the list, except the last one. Since $p_{n}=\tau_{n-1}$, we can simply apply lemma 4 directly to prove the inequality. For the final inequality, we know by the choice of $N$ and the construction of $\left\{p_{n}\right\}$ that $\tau_{N-1}=p_{N} \leq p \leq p_{N-1}$. The inequality follows by lemma 4 again. Q.E.D.

This proposition establishes that, under the usual partial equilibrium assumptions, the usual result that welfare is decreasing in price for prices greater than marginal cost holds. This is the central result of the paper. It establishes that moral hazard in medical markets is not, per se, an argument for prices higher than marginal costs in the medical market; thus it is not an argument for laxity in antitrust enforcement or for blockading entry in medical markets.

Although we do not offer an explicit argument, this result follows for a monopolist insurer as well, again because the monopolist insurer captures all surplus. In addition, it can also be shown that marginal cost prices are socially optimal if the insurer is a managed care organization that sets quantity given to a consumer on the basis of a signal of $\epsilon .^{2}$

\section{Summary and Conclusions}

In this paper we have considered what the appropriate competitive benchmark is for medical markets in the presence of moral hazard. Moral hazard due to insurance introduces a distortion into the medical market that requires analysis of the second-best. In the presence of moral hazard due to health insurance, consumers will demand "too much" medical care ex post. However, contrary to the conventional wisdom, if insurance markets are competitive, or possibly even if they are monopolized, consumers benefit from reduced prices in the medical market. Furthermore, provided that price exceeds marginal cost in the medical market, the benefit to consumers of a price decrease outweighs the loss in profits suffered by the medical industry. So, under the presumption that competition causes prices to fall in the medical industry, the mere existence of moral hazard should not cast doubt on the general intuition that more competition is socially beneficial. Further, moral hazard per se is not an argument for lax antitrust enforcement or for erecting barriers to entry in the medical market.

We must apply some caveats to these conclusions, however. In this paper we have analyzed only one of the distortions in medical markets:

\footnotetext{
${ }^{2}$ Proofs of both of these propositions are available on request from the authors.
} 
moral hazard. We have not considered other factors that are commonly cited in rendering competition in medical markets different: risk selection in insurance markets, agency problems in medical markets (i.e., induced demand), and the presence of not-for-profit firms. It remains for future research to consider the constellation of these imperfections in concert.

\section{Appendix}

\section{Proofs}

Proof of Lemma 1

Since the constraint on the insurance company is $\tau \in[0, p]$, we show that $\tau=p$ cannot be optimal. Since $E V(Y-m(\tau), \tau)$ is differentiable by the functional form assumptions and the assumptions on $g$, it will suffice to show that $(\partial / \partial \tau) E V(y-m(\tau), \tau)$ is negative at $\tau=p:$

$$
\begin{aligned}
\frac{\partial}{\partial \tau} E V(y-m(\tau), \tau) & =E\left\{\frac{\partial}{\partial \tau} \nu\left(Y-m(\tau)+\max _{x}\{-\tau x+g(x, \epsilon)\}\right)\right\} \\
& =E\left\{\nu^{\prime}(\cdot)\left[-\frac{\partial}{\partial \tau} m(\tau)-x^{*}(\tau, \epsilon)\right]\right\}
\end{aligned}
$$

(from the envelope theorem). Now, we evaluate $\partial m(\tau) / \partial \tau$ at $\tau=p$ :

$$
\begin{aligned}
m(\tau) & =E\left\{(p-\tau) x^{*}(\tau, \epsilon)\right\}, \\
\frac{\partial}{\partial \tau} m(\tau) & =E\left\{-x^{*}(\tau, \epsilon)+(p-\tau) \frac{\partial}{\partial \tau} x^{*}(\tau, \epsilon)\right\}, \\
\left.\frac{\partial}{\partial \tau} m(\tau)\right|_{\tau=p} & =-E\left\{x^{*}(\tau, \epsilon)\right\} .
\end{aligned}
$$

After substitution,

$$
\begin{aligned}
\left.\frac{\partial}{\partial \tau} E V(y-m(\tau), \tau)\right|_{\tau=p} & =E\left\{\nu^{\prime}(\cdot)\left[E\left\{x^{*}(p, \epsilon)\right\}-x^{*}(p, \epsilon)\right]\right\} \\
& =-\operatorname{Cov}\left[\nu^{\prime}(\cdot), x^{*}\right] \\
& <0 .
\end{aligned}
$$

The last inequality follows from the assumptions on $g$ and $\nu$. Since $g_{12}>0$ and $g_{11}<0, x^{*}$ must be increasing in $\epsilon$. However, since $g_{2}<0, \max _{x}\{-p x+g(x, \epsilon)\}$ must be decreasing in $\epsilon$. Thus the argument of $\nu$ is decreasing in $\epsilon$. Since $\nu$ is concave, $\nu^{\prime}$ is increasing in $\epsilon$. Thus both $\nu^{\prime}$ and $x^{*}$ are increasing in $\epsilon$, establishing the inequality. Q.E.D. 
Proof of Lemma 2

Suppose the contrary. Then since $p_{n} \geq 0$ and $p_{n}$ is nonincreasing (since $\tau_{n} \in$ $\left.\left[0, p_{n}\right]\right), p_{n} \rightarrow p_{*}>0$. But this implies that $\tau_{n} \rightarrow p_{*}$ for $p_{n+1}=\tau_{n}$. The theorem of the maximum then establishes that

$$
p_{*} \in \underset{\tau \in[0, p *]}{\arg \max }\left\{E\left\{\nu\left(-m\left(\tau, p_{*}\right)+\max _{x}\{-\tau x+g(x, \epsilon)\}\right)\right\}\right\} .
$$

This contradicts lemma 1 . Thus $p_{n} \rightarrow 0$. Q.E.D.

Proof of Lemma 3

Notice that

$$
\begin{gathered}
E\{U(Y-m(\tau, p)-\tau x(\tau, \epsilon), x(\tau, \epsilon), \epsilon)\} \\
=\exp [-r(Y-m(\tau, p))] E\{U(-\tau x(\tau, \epsilon), x(\tau, \epsilon), \epsilon)\},
\end{gathered}
$$

by our assumptions on the utility function, and that the values of this function are negative. Since $-(1 / r) \ln (-x)$ is a strictly increasing function, we can define

$$
\begin{gathered}
\hat{U}(Y-m(\tau, p)-\tau x(\tau, \epsilon), x(\tau, \epsilon), \epsilon) \\
=-\frac{1}{r} \ln [-E\{U(Y-m(\tau, p)-\tau x(\tau, \epsilon), x(\tau, \epsilon), \epsilon)\}]
\end{gathered}
$$

and maximize it instead. The solutions to

$$
\max _{\tau \in[0, p]} E\{U(Y-m(\tau, p)-\tau x(\tau, \epsilon), x(\tau, \epsilon), \epsilon)\}
$$

and

$$
\max _{\tau \in[0, p]} Y-m(\tau, p)-\frac{1}{r} \ln [-E\{U(-\tau x(\tau, \epsilon), x(\tau, \epsilon), \epsilon)\}]
$$

are the same. The cross partial of $\hat{U}$ with respect to $p$ and $\tau$ is nonnegative, at

$$
-\frac{\partial^{2} m}{\partial p \partial \tau}=-\frac{\partial x(\tau, \epsilon)}{\partial \tau} .
$$

Let $\tau$ be the largest maximizer at price $p$. Then for all $\tilde{\tau} \leq \tau, \hat{U}(\tau, p)-$ $\hat{U}(\tilde{\tau}, p) \geq 0$. Consider, now, price $p^{\prime}>p$. The cross-partial between $p$ and $\tau$ positive implies that

$$
\forall \tilde{\tau} \leq \tau, \hat{U}\left(\tau, p^{\prime}\right)-\hat{U}\left(\tilde{\tau}, p^{\prime}\right) \geq \hat{U}(\tau, p)-\hat{U}(\tilde{\tau}, p) \geq 0 .
$$

Also, $\tau$ continues to be feasible at $p^{\prime}$. Thus any maximizer under $p^{\prime}>p$ must be greater than or equal to $\tau$. Q.E.D.

Note that the argument in lemma 3 is a simple supermodularity argument (see Milgrom and Shannon 1994, theorem 4').

\section{Proof of Lemma 4}

We seek to show that 


$$
\begin{aligned}
W\left(p^{1}\right)= & E\left\{\nu\left(Y+\pi_{m}^{1}-m^{1}+\max _{x}\left\{-\tau^{1} x+g(x, \epsilon)\right\}\right)\right\} \\
\leq & \max _{\tau \in\left[0, p^{1}\right]} E\left\{\nu \left(Y+\pi_{m}^{1}-\left(p^{1}-p^{2}\right) E\left\{x^{*}\left(\tau^{1}, \epsilon\right)\right\}-m\left(\tau, p^{2}\right)\right.\right. \\
& \left.\left.+\max _{x}\{-\tau x+g(x, \epsilon)\}\right)\right\} \\
= & E\left\{\nu\left(Y+\pi_{m}^{1}-\left(p^{1}-p^{2}\right) E\left\{x^{*}\left(\tau^{1}, \epsilon\right)\right\}-m^{2}+\max _{x}\left\{-\tau^{2} x+g(x, \epsilon)\right\}\right)\right\} \\
\leq & E\left\{\nu\left(Y+\pi_{m}^{2}-m^{2}+\max _{x}\left\{-\tau^{2} x+g(x, \epsilon)\right\}\right)\right\} \\
= & W\left(p^{2}\right) .
\end{aligned}
$$

The first inequality follows since, when $\tau$ is set equal to $\tau^{1}$, the objective function in the second line is equal to the first line. The maximization assumption then guarantees the inequality. To show the second inequality, it will suffice to show that $\pi_{m}^{1}-\left(p^{1}-p^{2}\right) E x^{*}\left(\tau^{1}, \epsilon\right) \leq \pi_{m}^{2}$. Consider the following:

$$
\begin{aligned}
\pi_{m}^{1}-\left(p^{1}-p^{2}\right) E x^{*}\left(\tau^{1}, \epsilon\right) & =\left(p^{1}-c\right) E x^{*}\left(\tau^{1}, \epsilon\right)-\left(p^{1}-p^{2}\right) E x^{*}\left(\tau^{1}, \epsilon\right) \\
& =\left(p^{2}-c\right) E x^{*}\left(\tau^{1}, \epsilon\right) \\
& \leq\left(p^{2}-c\right) E x^{*}\left(\tau^{2}, \epsilon\right) \\
& =\pi_{m}^{2} .
\end{aligned}
$$

The inequality follows since $\tau(p)$ is nondecreasing and demand is downwardsloping (no income effects). Q.E.D.

\section{References}

Arnott, Richard J., and Stiglitz, Joseph E. "Equilibrium in Competitive Insurance Markets with Moral Hazard.” Working Paper no. 3588. Cambridge, Mass.: NBER, January 1991.

Arrow, Kenneth J. "Uncertainty and the Welfare Economics of Medical Care." A.E.R. 53 (December 1963): 941-73.

Bingaman, Anne K. "The Importance of Antitrust in Health Care." Utah Law Rev., no. 2 (1995), pp. 373-80.

Crew, Michael A. "Coinsurance and the Welfare Economics of Medical Care." A.E.R. 59 (December 1969): 906-8.

Dor, Avi, and Rizzo, John A. "The Welfare Effects of Mergers in a Service Industry." Manuscript. New Haven, Conn.: Yale Univ., 1995.

Feldman, Roger, and Dowd, Bryan. "A New Estimate of the Welfare Loss of Excess Health Insurance.” A.E.R. 81 (March 1991): 297-301.

Feldstein, Martin S. "The Welfare Loss of Excess Health Insurance." J.P.E. 81, no. 2, pt. 1 (March/April 1973): 251-80.

Folland, Sherman; Goodman, Allen C.; and Stano, Miron. The Economics of Health and Health Care. 3d ed. Upper Saddle River, N.J.: Prentice-Hall, 2001.

Frech, H. E., III. "Market Power in Health Insurance, Effects on Insurance and Medical Markets." J. Indus. Econ. 28 (September 1979): 55-72.

Competition and Monopoly in Medical Care. Washington: AEI Press, 1996.

Gaynor, Martin, and Haas-Wilson, Deborah. "Change, Consolidation, and Competition in Health Care Markets.” J. Econ. Perspectives 13 (Winter 1999): 141-64. 
Lynk, William J. "Nonprofit Hospital Mergers and the Exercise of Market Power." J. Law and Econ. 38 (October 1995): 437-61.

Milgrom, Paul, and Shannon, Chris. "Monotone Comparative Statics." Econometrica 62 (January 1994): 157-80.

Pauly, Mark V. "The Economics of Moral Hazard: Comment." A.E.R. 58 (June 1968): 531-37.

. "Overinsurance and Public Provision of Insurance: The Roles of Moral Hazard and Adverse Selection." O.J.E. 88 (February 1974): 44-62.

. "Managed Care, Markets, and Monopsony." Manuscript. Philadelphia: Univ. Pennsylvania, 1998.

Phelps, Charles E. Demand for Health Insurance: A Theoretical and Empirical Investigation. Report no. 1054-OEO. Santa Monica, Calif.: Rand Corp., July 1973.

Robinson, James C., and Luft, Harold S. "The Impact of Hospital Market Structure on Patient Volume, Average Length of Stay, and the Cost of Care." J. Health Econ. 4 (December 1985): 333-56.

Weller, Charles D. "The Primacy of Standard Antitrust Analysis in Health Care." Toledo Law Rev. 14 (Spring 1983): 609-37.

Willig, Robert D. "Consumer's Surplus without Apology.” A.E.R. 66 (September 1976): 589-97.

Zeckhauser, Richard. "Medical Insurance: A Case Study of the Tradeoff between Risk Spreading and Appropriate Incentives.” J. Econ. Theory 2 (March 1970): $10-26$. 